\title{
TAXONOMIC ACCOUNT OF JUMPING SPIDERS - GENUS Marpissa C. L. KOCH (ARACHNIDA: ARANEAE: SALTICIDAE) FROM BANGLADESH
}

\author{
Biswas, V. and D. Raychaudhuri ${ }^{1}$ \\ Department of Zoology, Khulna Govt. Womens' College, Khulna-9000, Bangladesh; ${ }^{\text {E Entomology }}$ \\ Laboratory, Department of Zoology, University of Calcutta, 35, Ballygunge Circular Road, Kolkata- \\ 700019, India
}

\begin{abstract}
A taxonomic study on the jumping spiders' genus Marpissa C.L. Koch, 1846 was carried out from different areas of Bangladesh. Four species were identified from the study, namely M. andamanensis Tikader, M. bengalensis Tikader, M. calcuttaensis Tikader and M. decorata Tikader. All the species are illustrated and described in detail for the first time in Bangladesh. Generic diagnosis, distribution and key to the species are also provided herewith.
\end{abstract}

Key words: Taxonomy; Jumping spider; Marpissa; Arachnida; Araneae; Salticidae.

\section{INTRODUCTION}

Jumping spiders (family Salticidae) are one of the common and fascinating groups of the predatory arachnids distributed throughout the world. They are usually found in a wide range of habitats and play an important role in the control of small insect pests, viz. green leaf hopper (GLH), brown plant hopper $(\mathrm{BPH})$, different orthopterans, dipterans etc., especially in the crop-fields, gardens and forests. The family at present comprises about 6115 species under 636 genera worldwide (World Spider Catalog 2021, Logunov and Marusik 2000), but in Bangladesh, their numbers are very poor and till date, only 72 species belonging to 21 genera are recorded (Biswas 2019) although a good number of species are described in the neighbouring Asian countries like - India (Roy et al. 2016), Pakistan (Butt and Beg 2000), China (Peng 2020), Japan (Baba 2013a,b), Korea (Kim et al. 2017), Singapore (Koh 1989), Vietnam (Proszynski 1992), The Philippines (Barrion and Litsinger 1995).

The spiders of the genus Marpissa are common members of the family Salticidae in the crop-fields, gardens and forests of Bangladesh. The genus was first established by Koch (1846) with the type-species M. muscosa Clerck. At present the genus comprises a total of 51 species in the world fauna (World Spider Catalog 2021) of which 17 species in India (Keswani et al. 2012). But taxonomic reports on these spiders are scarce in the fauna of Bangladesh (Biswas 2019).

Considering the importance of these arachnids, the present work was undertaken to find out their taxonomic position in Bangladesh. The present paper contains an illustrated description of four species of the genus Marpissa collected from different areas of the country.

\section{Collection and Preservation}

\section{MATERIAL AND METHODS}

The study was made with the collection of specimens from different areas of Bangladesh. Spiders were collected by vial trapping and shaking or jerking the branches of shrubs on an inverted umbrella placed underneath the plants. The collected specimens were then anesthetized using chloroform in a glass jar and were then transferred to a Petri dish filled with 70\% ethyl alcohol for sorting in the Entomology Laboratory, Department of Zoology, Calcutta University. During sorting, the specimens were placed in glass vials (single specimen vial) filled with $70 \%$ ethyl alcohol for identification. After identification, the specimens were finally preserved in Audmans' preservatives ( 90 parts $70 \%$ alcohol + 5 parts glycerine +5 parts glacial acetic acid) following Tikader (1987). 


\section{Identification and Deposition}

The preserved specimens were identified following the literatures of Biswas (2009), Peng (2020) and Zabka (1997).

The preserved specimens are at present in the collection of the Department of Zoology, Khulna Government Womens' College, Khulna and will be deposited to the Museum of the Department of Zoology, University of Dhaka, Dhaka-1000, Bangladesh, in due course of time.

\section{Dissection and Study}

Necessary body-parts of all the identified spiders were dissected out under the Stereo Zoom Binocular Microscope placed on a Petri dish filled with $70 \%$ alcohol and sand grains. Male palp after dissection was boiled in $10 \% \mathrm{KOH}$ for 3-5 minutes and female epigynum after dissection placed in clove oil for 12-18 hours (Tikader 1987). After dissection, male palp and female genitalia were placed in separate micro vials and put them in a large vial along with the parent spider within Audmans' preservatives.

\section{Illustration and Photographs}

The whole body of a spider and its body-parts were illustrated under a Stereo Zoom Binocular Microscope fitted with Camera Lucida. Leg measurements were taken under the same condition in the following sequence: femur, patella, tibia, metatarsus, tarsus and total length and all measurements were taken in millimeters $(\mathrm{mm})$.

Photographs of the species and their body parts were taken under a Camera fitted microscope (SV8, Zeiss) and by DSLR Camera with macro zoom lens.

\section{Taxonomy}

\section{RESULTS AND DISCUSSION}

Family: Salticidae Blackwall 1841

Subfamily: Marpissinae Simon 1901

Genus: Marpissa C. L. Koch 1846.

\section{Diagnosis}

The spiders of the genus Marpissa C. L. Koch are small to medium in size with broad and relatively flat carapace. Cephalothorax usually rectangular, larger than wide; width of carapace approximately $2 / 3^{\text {rd }}$ of carapace length. Eyes of anterior row sub-contiguous and the anteromedians twice or nearly twice larger than the anterolaterals and eyes of the $2^{\text {nd }}$ row smallest. Ocular area wider than long occupying 40-50 percent of carapace length. Chelicerae longer than wide, with 1 tooth on inner or retromargin and 2 teeth on the outer or promargin. Sternum narrower in front than base of labium.

Abdomen oval or elongately oval. First pair of legs two or three times as heavier as remaining pairs; leg formula in male 1423 and in female 1432. Tibiae and metatarsi I and II of both sexes with 3 and 2 pairs of ventral spines. Male palp with long embolus and narrow and bulb-like base. Tegulum large, saclike, cymbium with a deep sulcus along its prolateral margin. Tibiae of palp with an apophysis of variable shape. Female genitalia with a pair of long, coiled tubes.

The spider of this genus are large with broad and flat body. They live under loose bark of trees, on fences of gardens and outside of buildings. They hibernate in tight sac under bark logs and similar protected places. Most of the hibernating individuals mature in the spring. Some of them spin a firm cocoon, but in groups they form under loose bark of the dead trees (Kaston 1972). They can jump a 
good distance more than their body sizes. They are one of the good predators of small insect pests of crop-fields, gardens and forests. They catch preys by a peculiar jumping habit.

Distribution: America, Asia, Australia and Europe.

\section{Key to the species of Marpissa C. L. Koch}

1. Abdomen anteriorly broad, parallel sided, posteriorly narrowing........................................... 3

- Abdomen posteriorly broad, not parallel sided, anteriorly narrowing............................ 2

2. Cephalothorax parallel sided, medially with a fovea; hairs absent between the eyes; sternum parallel sided; median spinnerets produced, pointed, posterolaterals inwardly curved; outer margin of chelicerae with 3 similar teeth; epigyne as in Fig. 2e .............................. bengalensis

- Cephalothorax marginally convex, devoid of any fovea; long hairs present between the eyes; sternum marginally convex; median spinnerets semilunar, posterolaterals cylindrical; outer margin of chelicerae with 4 dissimilar teeth; epigyne as in Fig $4 \mathrm{e}$. decorata

3. Anteromedian eyes closely placed; inner margin of chelicerae with an indistinct tooth; Sternum posteriorly swollen, not spiny; median spinneret similar. andamanensis

- Anteromedian eyes distantly placed; inner margin of chelicerae with distinct teeth; sternum posteriorly truncate and spiny; median spinneret produced. calcuttaensis

\section{Marpissa andamanensis Tikader 1977 (Fig. 1a-f and Fig. 5a)}

Two females, Jhenaidah, 18. V.1992, Coll. V. Biswas; 1 male, 1 female, BARI, Jashore, 12.IX.1993, Coll. V. Biswas; 1 female, Digha, Rajshahi, 4. III. 1992, Coll. V. Biswas has been examined.

Female body is medium to large (Fig. 1a); Cephalothorax, legs and abdomen brown; Total body (female) length $12.00 \mathrm{~mm}$; Carapace $5.10 \mathrm{~mm}$ long, $3.80 \mathrm{~mm}$ wide; abdomen $6.90 \mathrm{~mm}$ long and 4.40 $\mathrm{mm}$ wide. Male is little smaller than female and small to medium. Total body length (male) $9.50 \mathrm{~mm}$; Carapace $4.00 \mathrm{~mm}$ long, $3.20 \mathrm{~mm}$ wide; abdomen $5.50 \mathrm{~mm}$ long and $4.00 \mathrm{~mm}$ wide.

Cephalothorax is longer than wide, anteriorly weakly narrowed and raised; cephalic region flat and clothed with fine hairs, few spines and pubescence; a longitudinal conspicuous white flame-like band distinct from the base of cephalothorax to the centre ocular area. Eyes are moderately large, anterior row pearly-white, anterolateral eyes slightly larger than the posterolaterals; $2^{\text {nd }}$ pair of eyes minute and situated between the anterior and posterior rows; ocular trapezium nearly squarish; Chelicerae brown, thick.

Tooth while outer margin with 2 rather large similar teeth (Fig. 1b). Maxillae and labium browngray, broad, former longer than wide, the latter wider than long, scopulate (Fig. 1c). Sternum narrowing at both ends with yellow hairs and yellow and brown erect spines (Fig. 1d). Leg I and II more robust, clothed with long hairs and spines; tibiae and metatarsi I and II with 3 and 2 pairs of ventral spines; leg formula 1243 and the measurements (in $\mathrm{mm}$ ) as shown in Table 1.

Abdomen is oval, posteriorly narrowed, abdominal hairs variably developed, fine, short to long; mid-dorsally with a longitudinal white band; ventrally pale brown, densely hairy; epigyne as in Fig 1e. 


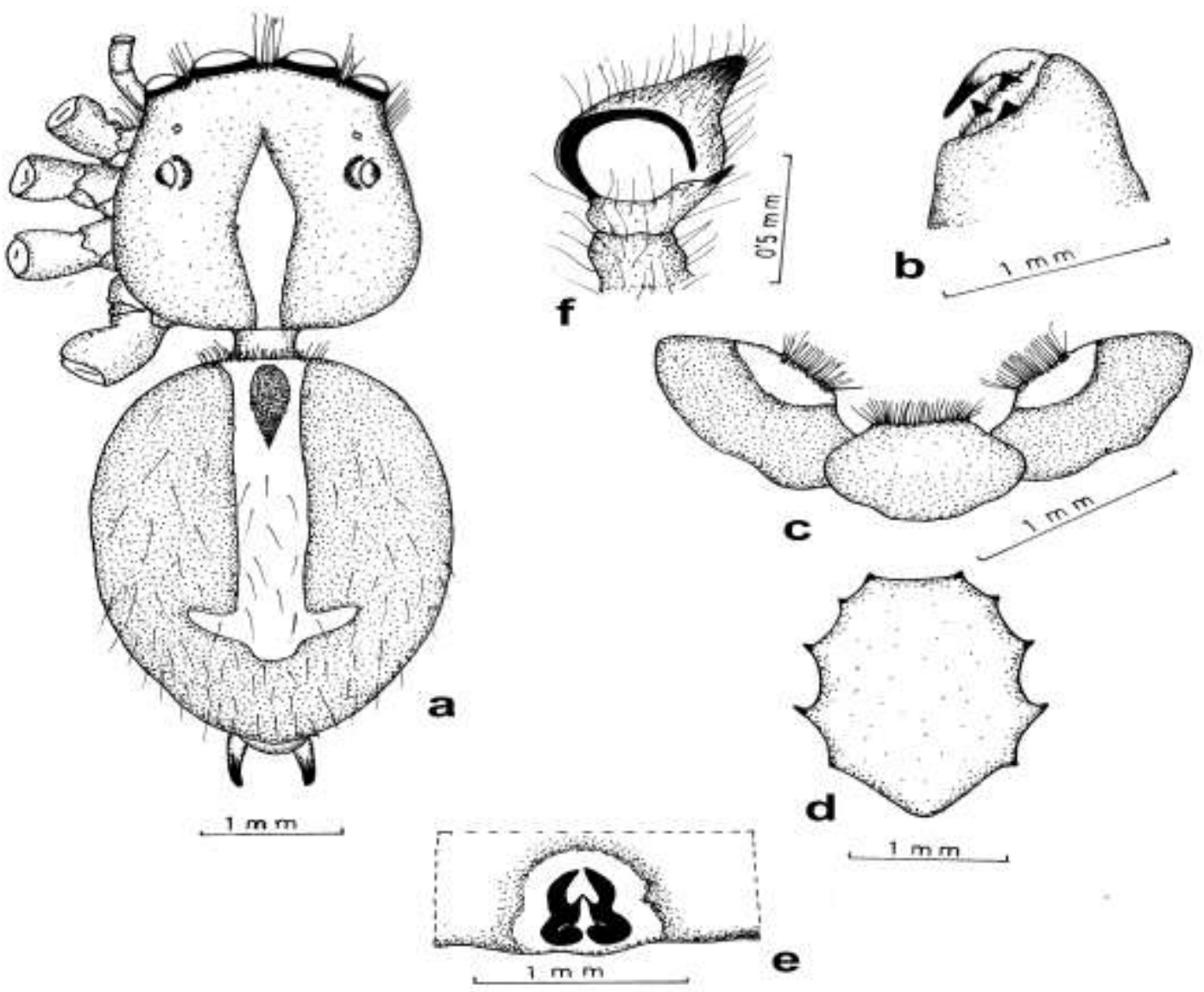

Fig. 1. Marpissa andamanensis Tikader: a. Whole body (dorsal view); b. Chelicerae; c. Maxillae and Labium; d. Sternum; e. Epigynum; and f. Male palp.

Male is small in size, much smaller than the female, dark brown in colour and robust. Cephalothorax is broad; dark brown with small dense hairs. Anterior row of eyes slightly recurved; median eyes much smaller; each eyes encircled by black band; Chelicerae brown, strong, each of inner and outer margins with 1 and 2 teeth, respectively; Maxillae longer than wide, light brown, scopulate anteriorly; Sternum light brown, elongately oval, posteriorly bluntly pointed; Legs robust, with sharp spines; Male palps is as in Fig. 1f.

Table 1. Measurements (in mm) of the leg segments of Marpissa andamanensis Tikader.

\begin{tabular}{cccccc}
\hline Leg & Femur & Patella \& Tibia & Metatarsus & Tarsus & Total \\
\hline I & $1.50 / 1.50$ & $2.00 / 2.00$ & $0.80 / 0.80$ & $0.60 / 0.60$ & $4.90 / 4.90$ \\
II & $1.30 / 1.30$ & $2.20 / 2.20$ & $0.70 / 0.70$ & $0.50 / 0.50$ & $4.70 / 4.70$ \\
III & $1.30 / 1.30$ & $1.80 / 1.80$ & $0.60 / 0.60$ & $0.50 / 0.50$ & $4.20 / 4.20$ \\
IV & $1.40 / 1.40$ & $1.90 / 1.90$ & $0.80 / 0.80$ & $0.50 / 0.50$ & $4.60 / 4.60$ \\
\hline
\end{tabular}

Abdomen is oval, a little wide medially; covered with small hairs; ventrally pale; Dorsum with white longitudinal band; lateral spinnerets are elongate, median blunt.

Distribution: Jashore, Jhenaidah and Rajshahi in Bangladesh (Biswas 2019); India (Proszynski 1990). 


\section{Marpissa bengalensis Tikader 1974 (Fig. 2a-e and Fig. 5b)}

Two females, Bagerhat, 12. V. 1990, Coll. V. Biswas; 2 females, Botiaghata, Khulna, 18. VII. 1992, Coll. V. Biswas; 2 females, Manikgonj, 12.IX.1990, Coll. V. Biswas; 1 female, R.U. Campus, Rajshahi, 04.III. 1992, Coll. V. Biswas has been examined.
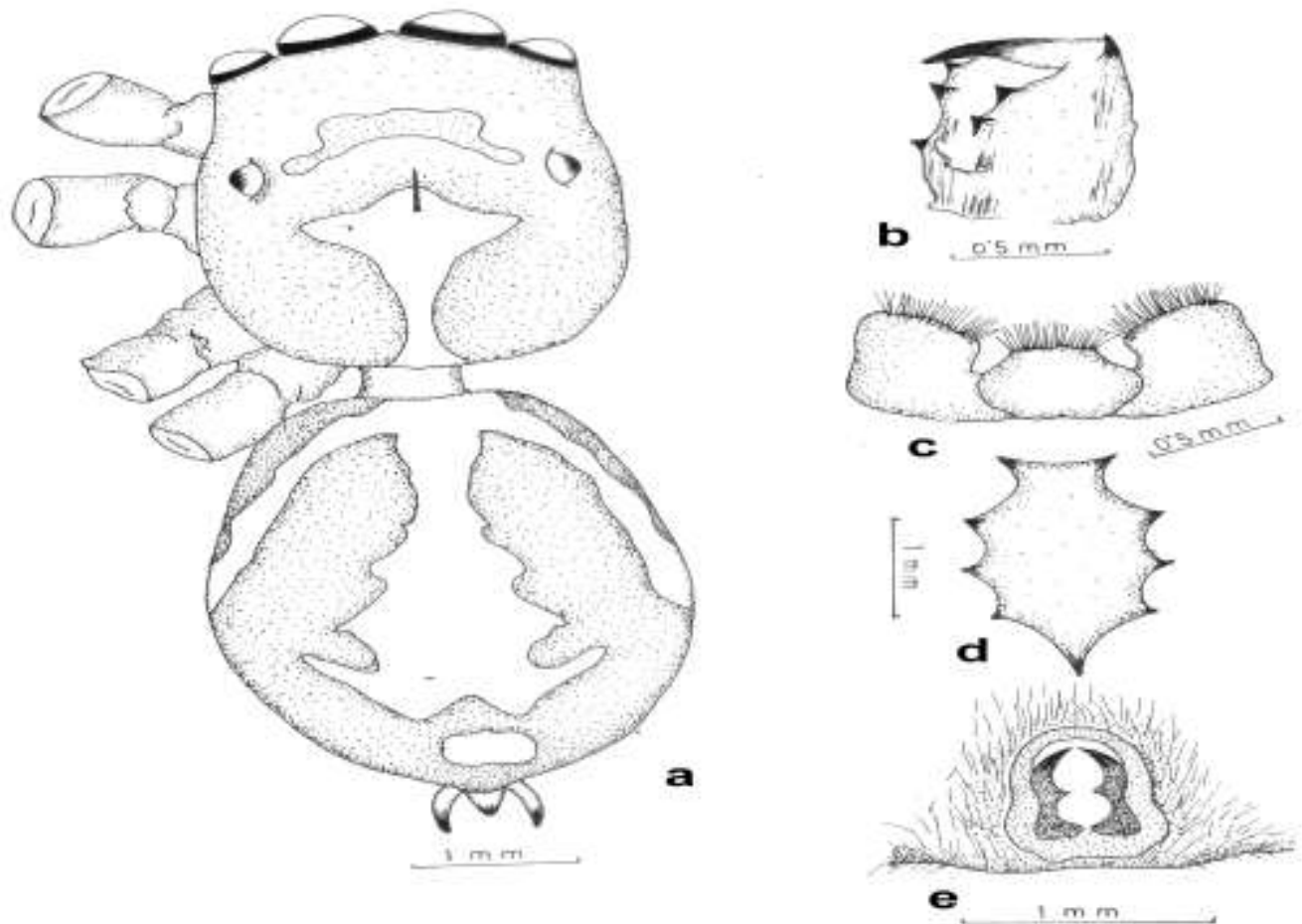

Fig. 2. Marpissa bengalensis Tikader: a. Whole body (dorsal view); b. Chelicerae; c. Maxillae and Labium; d. Sternum; and e. Epigynum.

Female body is small to medium, brown in colour; Cephalothorax brown; legs yellow brown; abdomen pale brown; Total body length $8.25 \mathrm{~mm}$; Carapace $4.00 \mathrm{~mm}$ long, $3.00 \mathrm{~mm}$ wide; abdomen $4.25 \mathrm{~mm}$ long and $3.00 \mathrm{~mm}$ wide.

Table 2. Measurements (in mm) of the leg segments of Marpissa bengalensis Tikader.

\begin{tabular}{cccccc}
\hline Leg & Femur & Patella \& Tibia & Metatarsus & Tarsus & Total \\
\hline I & $1.50 / 1.50$ & $1.90 / 1.90$ & $1.00 / 1.00$ & $0.60 / 0.60$ & $5.00 / 5.00$ \\
II & $1.30 / 1.30$ & $1.80 / 1.80$ & $0.90 / 0.90$ & $0.50 / 0.50$ & $4.50 / 4.50$ \\
III & $1.20 / 1.20$ & $1.80 / 1.80$ & $0.70 / 0.70$ & $0.50 / 0.50$ & $4.20 / 4.20$ \\
IV & $1.40 / 1.40$ & $1.90 / 1.90$ & $0.80 / 0.80$ & $0.50 / 0.50$ & $4.60 / 4.60$ \\
\hline
\end{tabular}

Cephalothorax rectangular, posteriorly wide, anteriorly raised, clothed with fine black hairs and pubescence; cephalic region raised. Eyes pearly-white, saving milky-white anteromedians; anterior row of eyes recurved, bases of which encircled by black patches, anteromedians nearly 4 times larger than the anterolaterals; $2^{\text {nd }}$ pair of eyes minute, placed equidistantly from the anterior and posterior rows; posterior row of eyes smaller than the anterolaterals. Cephalothorax with a distinct fovea at the centre, besides a semilunar band between the posterior eyes and a typical white vase-shaped band at the posterior half. Chelicerae red-brown, strong, inner and outer margins with 2 and 3 teeth, fang flat (Fig. 2b). Maxillae and labium pale brown, basally broad and anteriorly scopulate (Fig. 2c). Sternum pale 
yellow, vase-shaped (Fig.2d). Legs long, slender, I and II robust, clothed with long, grey hairs and spines; tibiae and metatarsi I and II with 3 and 2 pairs of ventral spines respectively; leg formula 1423 and the measurements (in $\mathrm{mm}$ ) as shown in Table 2.

Abdomen is nearly oval, posteriorly broad, closed with fine hairs and pubescence; dorsum decorated with white bands; ventrally pale with irregular brown spots, clothed with brown hairs and pubescence; epigyne as in Fig. 2e.

Distribution: Bagerhat, Manikgonj and Rajshahi in Bangladesh (Biswas 2009); in India (Tikader 1974).

\section{Marpissa calcuttaensis Tikader 1974 (Fig. 3a-e and Fig. 5c)}

Female body medium in size, dark brown. Cephalothorax dark brown; legs and abdomen yellow brown. Total body length $7.30 \mathrm{~mm}$. Carapace $3.60 \mathrm{~mm}$ long, $2.80 \mathrm{~mm}$ wide; abdomen $3.70 \mathrm{~mm}$ long and $2.60 \mathrm{~mm}$ wide.

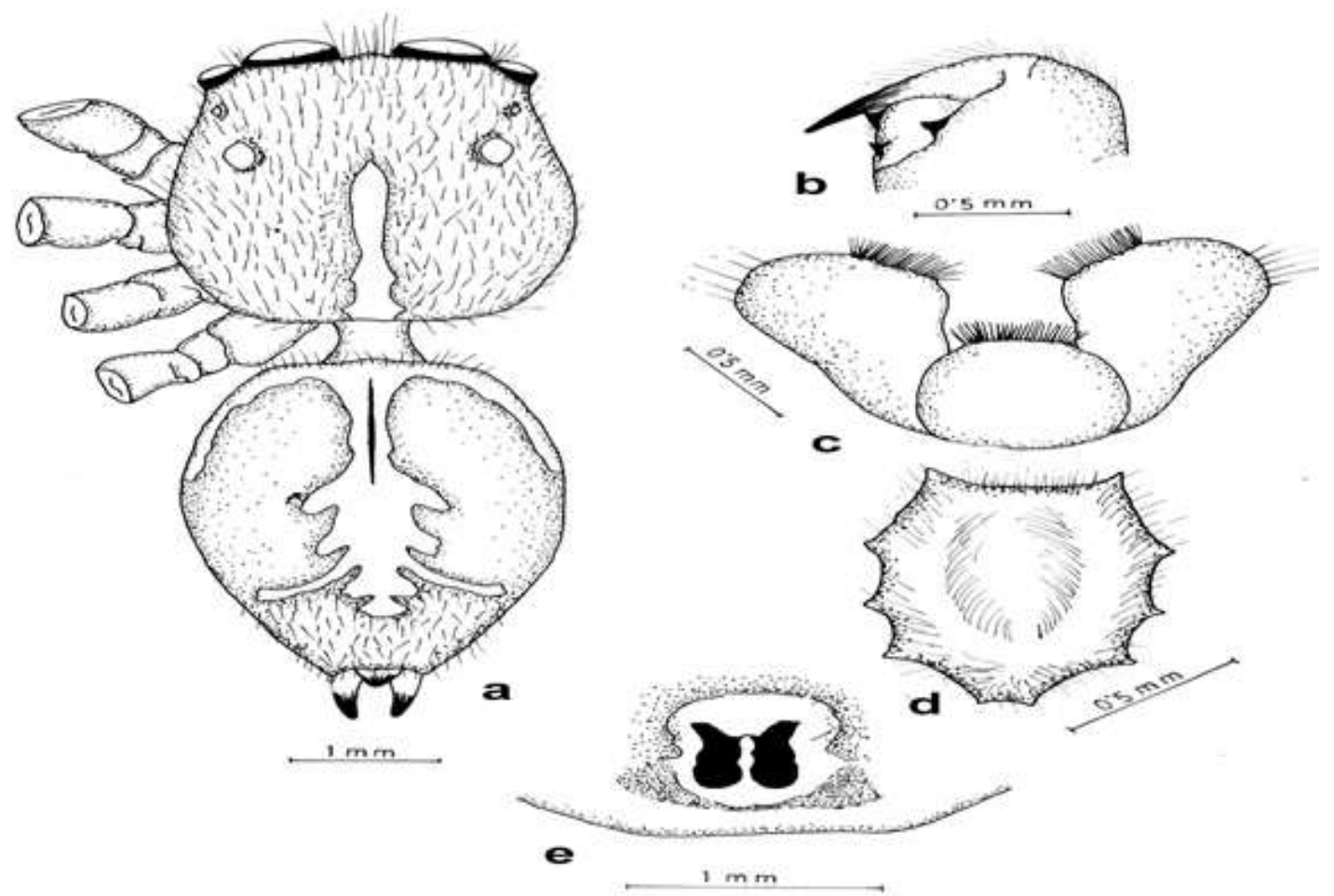

Fig. 3. Marpissa calcuttaensis Tikader: a. Whole body (dorsal view); b. Chelicerae; c. Maxillae and Labium; d. Sternum; and e. Epigynum.

Cephalothorax is broad, longer than wide; cephalic region flat, medially pale, without fovea. Eyes pearly-white excepting the milky-white anteromedians; anterior row of eyes slightly recurved while the other rows straight; anteromedians nearly 2 times larger than the anterolaterals; eyes of the middle row minute, situated equidistantly from the anterior and posterior rows and placed rather marginally; ocular trapezium wider than long and slightly elevated; cephalothorax centrally with a longitudinal white band, clothed with hairs, spines and pubescence. Chelicerae pale brown, broad, inner and outer margins with 1 and 2 teeth respectively; fang basally wide (Fig. 3b). Maxillae yellow-brown, longer than wide, anteriorly clubbed and scopulate (Fig. 3c). Labium yellow brown, broad, rounded, scopulate anteriorly (Fig. 3c). Sternum yellow, elongate, concave anteriorly, clothed with hairs and spines (Fig. 3d). Legs strong and stout, clothed with hairs and spines; tibiae and metatarsi I and II with 3 and 2 pairs of ventral spines respectively; leg formula 4132 and the measurements (in $\mathrm{mm}$ ) as shown in Table 3. 
Table 3. Measurements (in mm) of the leg segments of Marpissa calcuttaensis Tikader.

\begin{tabular}{cccccc}
\hline Leg & Femur & Patella \& Tibia & Metatarsus & Tarsus & Total \\
\hline I & $1.40 / 1.40$ & $1.90 / 1.90$ & $1.00 / 1.00$ & $0.60 / 0.60$ & $4.90 / 4.90$ \\
II & $1.30 / 1.30$ & $1.80 / 1.80$ & $0.60 / 0.60$ & $0.50 / 0.50$ & $4.20 / 4.20$ \\
III & $1.30 / 1.30$ & $2.10 / 2.10$ & $0.70 / 0.70$ & $0.50 / 0.50$ & $4.60 / 4.60$ \\
IV & $1.50 / 1.50$ & $2.20 / 2.20$ & $1.00 / 1.00$ & $0.70 / 0.70$ & $5.40 / 5.40$ \\
\hline
\end{tabular}

Abdomen is longer than wide, posteriorly narrowed, clothed with brown and yellow hairs and pubescence; dorsum decorated with brown and white patches; ventrally pale-yellow, with spines and hairs; epigyne as in Fig. 3e.

Distribution: Bagerhat, Chittagong, Comilla, Jashore, Kustia and Pabna in Bangladesh (Biswas 2009); in India (Proszynski 1990).

\section{Marpissa decorata Tikader 1974 (Fig. 4a-e and Fig. 5d)}

Two females, Jhenaidah, 02. II. 1992, Coll. V. Biswas; 2 females, Kustia, 02. V. 1992, Coll. V. Biswas; 2 females, Rajbari, 01. IX. 1993, Coll. V. Biswas; 1 female, R.U. campus, Rajshahi, 04. III. 1992, Coll. V. Biswas has been examined.

Female body is medium in size, reddish brown. Cephalothorax reddish brown; legs brown; abdomen brown with white markings. Total body length $7.20 \mathrm{~mm}$. Carapace $3.50 \mathrm{~mm}$ long, $2.80 \mathrm{~mm}$ wide; abdomen $3.70 \mathrm{~mm}$ long and $2.50 \mathrm{~mm}$ wide.

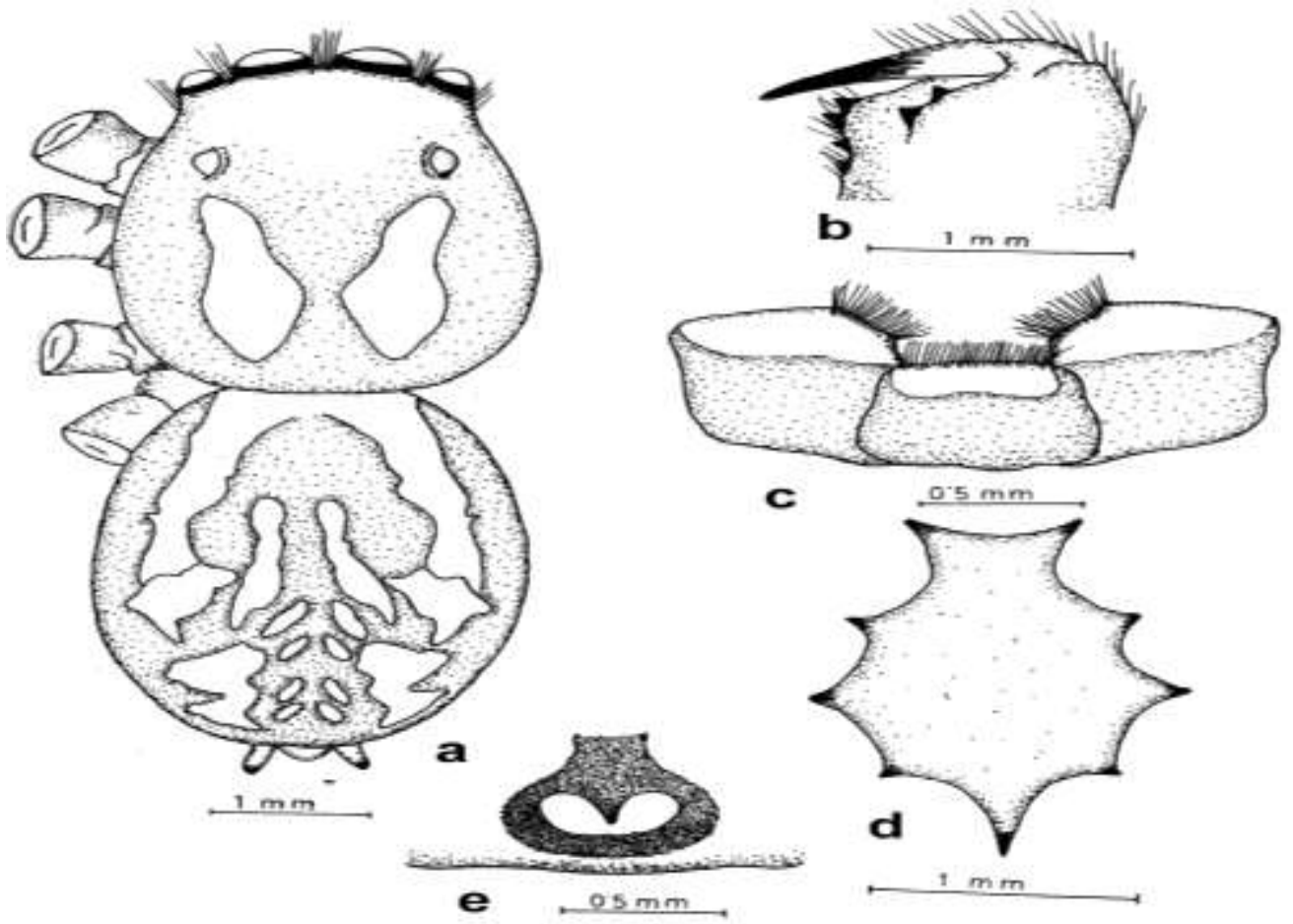

Fig. 4. Marpissa decorata Tikader: a. Whole body (dorsal view); b. Chelicerae; c. Maxillae and Labium; d. Sternum; and e. Epigynum.

Cephalothorax is broad, longer than wide, wider medially, with two longitudinal white patches; cephalic region narrowing anteriorly, with long hairs and pubescence; thoracic region clothed with pubescence. Eyes black, dissimilar; anterior row of eyes slightly recurved, each ringed with black 
patches, anteromedians twice larger than the anterolatrals; $2^{\text {nd }}$ row of eyes minute; posterior row of eyes smaller; ocular trapezium wider than long.

Table 4. Measurements (in mm) of the leg segments of Marpissa decorata Tikader.

\begin{tabular}{cccccc}
\hline Leg & Femur & Patella \& Tibia & Metatarsus & Tarsus & Total \\
\hline I & $1.40 / 1.40$ & $1.90 / 1.90$ & $1.00 / 1.00$ & $0.90 / 0.90$ & $5.20 / 5.20$ \\
II & $1.20 / 1.20$ & $1.60 / 1.60$ & $1.00 / 1.00$ & $0.80 / 0.80$ & $4.60 / 4.60$ \\
III & $1.30 / 1.30$ & $1.80 / 1.80$ & $1.00 / 1.00$ & $0.90 / 0.90$ & $5.00 / 5.00$ \\
IV & $1.50 / 1.50$ & $2.20 / 2.20$ & $1.20 / 1.20$ & $1.00 / 1.00$ & $5.90 / 5.90$ \\
\hline
\end{tabular}

Chelicerae brown, strong, inner and outer margins with 2 similar and 4 dissimilar teeth respectively (Fig. 4b). Maxillae and labium pale brown, both anteriorly scopulate (Fig. 4c). Sternum brown, irregularly vase-shaped, with long yellow hairs (Fig. 4d). Leg I and II robust, clothed with long hairs and spines; tibiae and metatarsi I and II with 3 and 2 pairs of ventral spines respectively; leg formula 4132 and the measurements (in $\mathrm{mm}$ ) as shown in Table 4.
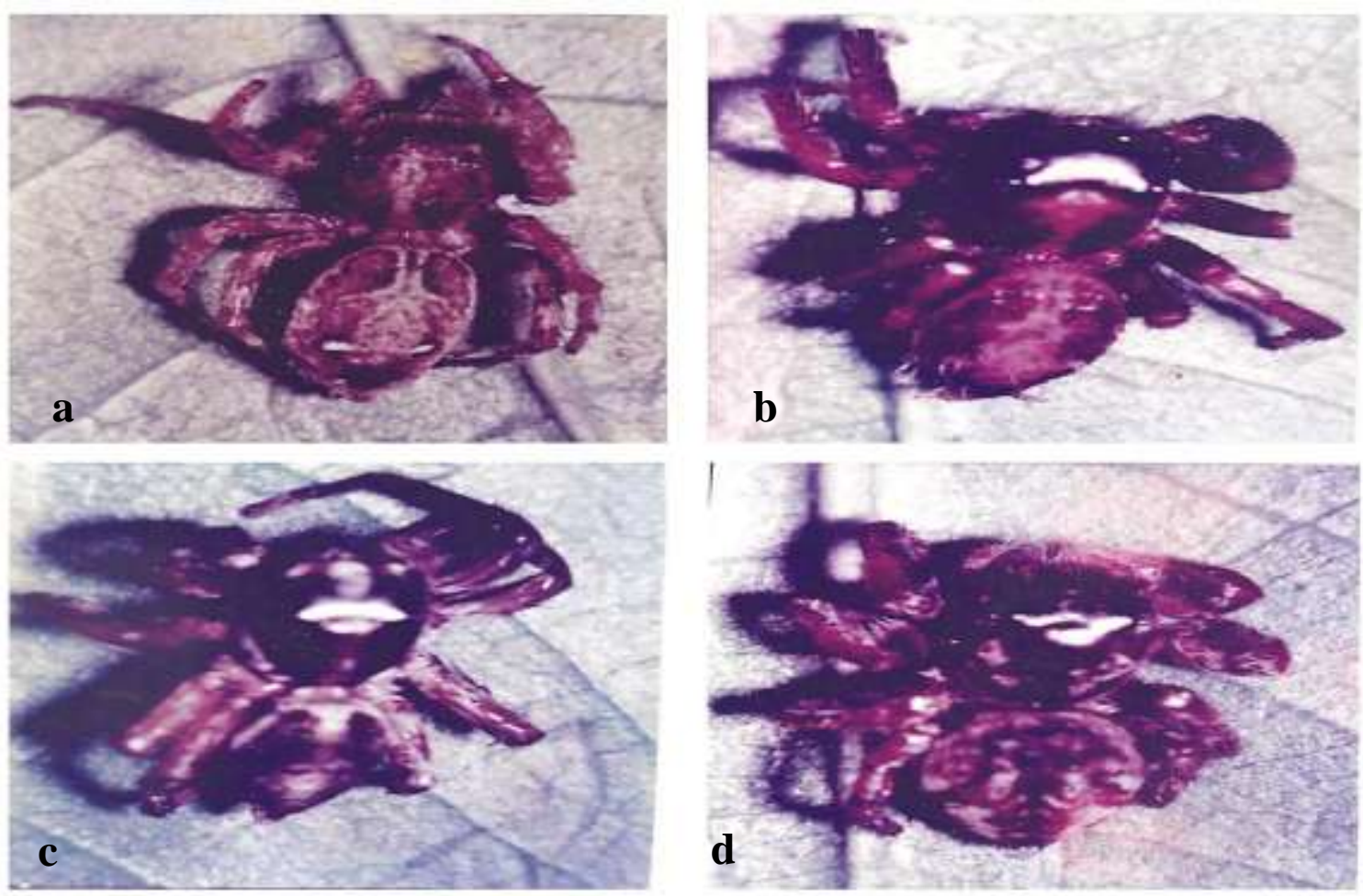

Fig. 5. Pictorial view of described species (dorsal view): a. Marpissa andamanensis Tikader; b. Marpissa bengalensis Tikader; $\boldsymbol{c}$. Marpissa calcuttaensis Tikader; and d. Marpissa decorata Tikader.

Abdomen is oval, longer than wide, narrowing anteriorly, with hairs and pubescence; dorsum decorated with white and black patches, ventrally white, medially with a longitudinal brown patch extending from the epigastric fold to the base of spinnerets, with dense pubescence; epigyne as in Fig. $4 \mathrm{e}$.

Distribution: Jhenaidah, Kustia, Rajbari and Rajshahi in Bangladesh (Biswas 2009); India (Proszynski 1990). 


\section{ACKNOWLEDGEMENTS}

The authors are grateful to Dr. S. C. Majumder, Scientist-SD, Arachnida Section, Zoological Survey of India, Kolkata, for the confirmation of the species identification and the Head, Department of Zoology, University of Calcutta, for kind permission during the course of this study.

\section{REFERENCES}

Baba, Y. G. 2013a. A new species of genus Marpissa (Araneae: Salticidae) of Japan. Acta Arachnol. 62(1): 51-53.

Baba, Y. G. 2013b. Two new species of jumping spiders (Araneae: Salticidae) from Japan. Acta Arachnol. 62(2): 103-107.

Biswas, V. 2009. Arachnida. In: Ahmed (ed.). Encyclopedia of flora and fauna of Bangladesh. Vol. 18(1). Asiatic Society of Bangladesh, Dhaka, Bangladesh. 437 pp.

Biswas, V. 2019. Checklist of the spider fauna of Bangladesh (Araneae: Arachnida). Bangladesh J. Zool. 47(2): 185-227.

Kaston, B. J. 1972. How to know the spiders? The pictured key nature series. Wm. C. Brown Co. Ltd, Dbubuque, Iowa, USA. 172 pp.

Keswani, S., P. Hadole and A. Rajoria. 2012. Checklist of spiders (Arachnida: Araneae) from India 2012. Indian J. Arachnol. 1(1): 1-129.

Kim, T. W., S. H. Ye, S. H. Ji, D. H. Kim, S. H. Ji, J. K. Byun, H. M. Lee and J. P. Kim. 2017. A newly recorded species of the genus Marpissa C. L. Koch, 1846 from Korea. Korean Arachnol. 33(2): 5-8.

Koh, J. K. H. 1989. A guide to common Singapore Spiders. Singapore Science Centre, Singapore. 160 pp.

Logunov, D. V. and Y. M. Marusik. 2000. Catalogue of the jumping spiders of Northern Asia. (Arachnida: Araneae: Salticidae). KMK Scientific Press, Moscow, Russia. 299 pp.

Peng, X. J. 2020. Fauna Sinica, Invertebrata (Arachnida: Araneae: Salticidae). Vol. 53. Science Press, Beijing, China. 611 pp.

Proszynski, J. 1990. Catalogue of Salticidae (Araneae). Synthesis of quotations in the world literature since 1940, with basic taxonomic data since 1758, WSRP, Siedlce. 366 pp.

Proszynski, J. 1992. Salticidae (Araneae) of India in the collection of the Hungarian National Natural History Museum in Budapest. Ann. Zool. Warszawa. 44(9): 165-277.

Roy, T. K., S. Saha and D. Raychaudhuri. 2016. A treatise on the jumping spiders (Araneae: Salticidae) of tea ecosystem of Dooars, West Bengal, India. World Scientific News. 53(1): 1-10.

Tikader, B. K. 1974. Studies on some spiders of genus Marpissa from India (Family: Salticidae). Proc. Indian Acad. Sci. 79(1-6): 204-2

Tikader, B. K. 1987. Handbook of Indian Spiders. Zoological Survey of India, Kolkata, India. 251 pp. 
